\section{Distribuição geográfica e características epidemiológicas da leishmaniose tegumentar americana em áreas de colonização antiga do Estado do Paraná, Sul do Brasil}

\author{
Geographic distribution and epidemiological \\ features of American tegumentary leishmaniasis \\ in old rural settlements in Paraná State, \\ Southern Brazil
}

\author{
Wuelton Marcelo Monteiro ${ }^{1}$ \\ Herintha Coeto Neitzke 2 \\ Maria Valdrinez Campana Lonardoni 3 \\ Thaís Gomes Verzignassi Silveira 3 \\ Maria Eugênia Moreira Costa Ferreira ${ }^{4}$ \\ Ueslei Teodoro ${ }^{3}$
}

\section{Introdução}

A incidência da leishmaniose tegumentar americana vem aumentando na América Latina, principalmente no Brasil, que registrou $605.062 \mathrm{ca}-$ sos, no período de 1980 a 2005 1. Nesse período, $13.384(2,2 \%)$ casos foram notificados na Região Sul do país, dos quais 13.206 (98,7\%) no Estado do Paraná 1 .

Desde o início do século passado, casos humanos de leishmaniose tegumentar americana têm sido relatados no norte, oeste e sudeste do Estado do Paraná. No norte, a doença alcançou proporções epidêmicas entre os anos de $1930 \mathrm{e}$ 1950, quando o estado passava por franco processo de colonização. A incidência caiu drasticamente durante a década de 50, como benefício indireto das campanhas para a erradicação da malária, por meio do uso de inseticidas 2. Desde 1980, contudo, a leishmaniose tegumentar americana voltou a se manifestar, tornando-se endêmica no Paraná 3,4,5.

As infecções humanas no Paraná são causadas principalmente pela espécie Leishmania braziliensis (Vianna) ${ }^{4}$. As espécies de flebotomíneos dominantes são Nyssomyia whitmani (Antunes \& Coutinho) e Nyssomyia neivai (Pinto) 6,7,8,9, sendo que a primeira foi encontrada naturalmente infectada por L. braziliensis no norte do estado 2. Alguns trabalhos mostram que os flebotomíneos têm sido coletados em grande número em zonas rurais onde as habitações têm condições precá- 
rias de higiene, há acúmulo de matéria orgânica (folhas e frutos caídos, fezes de animais domésticos e restos de alimentos a eles oferecidos) no peridomicílio, a umidade do solo é elevada e os abrigos de animais domésticos são próximos do domicílio, observando-se ainda a presença de matas remanescentes de tamanhos variados na proximidade das residências 6,7,8,9,10,11. Nesse contexto, a leishmaniose tegumentar americana persiste, mesmo com a substituição da vegetação originaldeflorestas pelas culturas decafé, soja, milho, algodão e por pastagens 5 , afetando cães 12,13 e humanos de todos os grupos etários e de ambos os sexos $3,4,5$.

No Estado do Paraná, a distribuição geográfica dos casos de leishmaniose tegumentar americana mostrou alta prevalência no norte e oeste 5 . As informações a respeito da distribuição espacial da leishmaniose tegumentar americana são importantes, pois permitem formular hipóteses sobre os principais determinantes ambientais da produção da doença e auxiliam no planejamento das ações de saúde, principalmente nas atividades de controle de vetores 14. Faltam, porém, informações mais detalhadas sobre os determinantes da distribuição da doença, nesse estado.

Procurou-se, neste trabalho, avaliar o papel do processo de ocupação dos espaços agrário e urbano como condição de risco para a ocorrência da leishmaniose tegumentar americana e determinar, de forma preliminar, os fatores espaciais que concorrem para a produção desta doença nas mesorregiões norte central, centro ocidental e noroeste do Estado do Paraná.

\section{Métodos}

\section{Área de estudo}

As mesorregiões norte central, centro ocidental e noroeste do Estado do Paraná situam-se en-

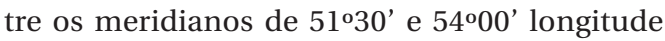
oeste e os paralelos de $22^{\circ} 30^{\prime}$ e $24^{\circ} 35^{\prime}$ latitude sul, abrangendo 162 municípios, numa área de $61.250,8 \mathrm{~km}^{2}$ e uma população de 2.816 .800 habitantes, com 2.364 .414 (83,9\%) na zona urbana e 452.386 (16,1\%) na zona rural (Censo Demográfico 2000. http:/ / www.ibge.gov.br, acessado em 05/Fev/2005)

As mesorregiões supracitadas, em conjunto com o oeste de São Paulo e sul do Mato Grosso do Sul, foram ocupadas durante a primeira metade do século XX, constituindo zonas agrícolas pioneiras do Brasil 15. A vegetação nativa, na sua maior parte destruída, era constituída por floresta estacional semidecidual, com queda parcial das folhas de certas espécies arbóreas no inverno, quando ocorre seca pouco pronunciada. No Paraná, as raras manchas dessa floresta tropical ou subtropical de transição encontram-se, ainda, precisamente nas margens dos rios Ivaí, Paranapanema, Paraná e de seus afluentes. O clima é tropical de transição para subtropical, apresentando temperaturas médias anuais entre $20^{\circ} \mathrm{C}$ e $22^{\circ} \mathrm{C}$, com média do mês mais quente superior a $22^{\circ} \mathrm{C}$, e invernos brandos com períodos de seca hibernal pouco pronunciada, dos meses de julho a setembro 16. A precipitação anual avaliada por um período de cinco anos indica média de $1.600 \mathrm{~mm} / \mathrm{ano}$, sendo novembro o mês mais chuvoso e agosto o mais seco 16 .

As mesorregiões abrangidas no presente estudo pertencem ao Terceiro Planalto Paranaense, constituído por derrames de lavas básicas intercaladas em estratos de arenito, cuja inclinação decai suavemente para oeste, em direção ao rio Paraná 16 . A paisagem, no seu conjunto, é de planalto levemente ondulado, com amplos interflúvios e vales abertos, embora os rios possam ocorrer em leitos por vezes encaixados, como é o caso dos rios Paraná e Ivaí, em alguns trechos. Os terrenos onde aflora a cobertura suprabasáltica (Arenito Caiuá) e outras formações cenozóicas, que sucederam o derrame de lava do Mesozóico, apresentam relevo mais aplainado, em mesetas, tal como ocorre no interflúvio Pirapó-Bandeirantes do Norte e no divisor Ivaí-Piquiri 16.

Os indicadores e mapas temáticos do Estado do Paraná, elaborados pelo Instituto Paranaense de Desenvolvimento Econômico e Social 17, mostram que a maioria dos municípios das mesorregiões norte central, centro ocidental e noroeste estão classificados no nível médio inferior de desenvolvimento humano, apresentando as seguintes características sócio-econômicas e demográficas: (1) as mesorregiões norte central e centro ocidental têm o setor primário como o mais importante, quanto à participação setorial no valor adicionado fiscal, enquanto a mesorregião norte central apresenta maior importância do setor terciário; (2) a agropecuária extensiva contribui com a maior parcela do valor bruto da produção silvoagropecuária nessas mesorregiões; (3) os gêneros industriais mais importantes são os de bens de consumo não duráveis, principalmente alimentos, têxteis, confecções e móveis; (4) a maioria dos municípios vem apresentando taxas negativas de crescimento da população total, desde 1970 até 2000; (5) o crescimento geométrico da população rural, entre 1991 e 2000, foi negativo nas três mesorregiões e positivo para a população urbana, no mesmo período; (6) o principal componente do déficit habitacional é a co-habitação familiar, seguida pelo ônus exces- 
sivo com aluguel e pelas habitações precárias, sendo que a variação do déficit habitacional é negativa na zona rural; e (7) as mesorregiões do estudo apresentam o maior grau de desigualdade de renda do Estado do Paraná.

\section{Procedimentos}

O estudo, retrospectivo e descritivo, foi realizado com base em dados registrados em fichas epidemiológicas do Laboratório de Ensino e Pesquisa em Análises Clínicas da Universidade Estadual de Maringá (LEPAC/UEM), centro de referência para leishmaniose tegumentar americana no Sul do Brasil, de 1987, quando foram implantados os testes para o diagnóstico da leishmaniose tegumentar americana neste laboratório, a 2004. Os dados coletados foram: número de casos de leishmaniose tegumentar americana ano a ano, município de residência, sexo, tipo de moradia, município mais provável de infecção, atividade que exercia no momento da infecção, idade, ocupação principal e zona residencial (rural/urbana). Foram considerados com diagnóstico laboratorial positivo os pacientes que apresentaram resultado positivo em pelo menos um dos seguintes testes: pesquisa parasitológica de Leishmania, imunofluorescência indireta (título $\geq 40$ ) ou reação intradérmica de Montenegro (diâmetro $\geq 5 \mathrm{~mm}$, após 48 a 72 horas da inoculação).

Para se avaliar, ainda que preliminarmente, as condições que podem favorecer a ocorrência da leishmaniose tegumentar americana, procedeu-se a análise de alguns aspectos geográficos - populacionais e sócio-econômicos. A metodologia adotada na análise dos resultados utilizou conceitos próprios da organização social do espaço 18,19 , buscando-se entender a persistência da endemia, apesar da sucessão de eventos sociais modificadores do espaço.

O conceito de "migrante", no âmbito deste trabalho, corresponde à categoria de "migrante de retorno" 20, tratando-se dos indivíduos que empreendem múltiplas ou repetidas migrações, retornando eventualmente ao ponto de origem, mas não de forma definitiva; este migrante não se fixa definitivamente na origem nem no destino, pois a migração representa um ponto de contato permanente entre um e outro. Abordou-se, ainda, a questão da mobilidade pendular como facilitadora da produção da leishmaniose tegumentar americana na área de estudo. O entendimento desses conceitos deve levar em consideração as oportunidades de trabalho e as estratégias para assegurar a reprodução de suas condições de existência.

Conforme o provável local de infecção, os casos foram divididos em duas categorias: (1) autóctones: indivíduos que provavelmente adquiriram a infecção no domínio doméstico e, (2) alóctones: indivíduos que provavelmente se infectaram fora do domínio doméstico. Entende-se por domínio doméstico, o "local da residência e do seu entorno, onde um grupo familiar desenvolve suas diversas atividades" 21 (p. 41), incluindo, no presente trabalho, o domicílio, o peridomicílio e, nos casos rurais, a propriedade agrícola onde reside.

Vale salientar que as deficiências no preenchimento e a falta de informação em um ou mais campos da ficha epidemiológica (idade, município mais provável de infecção, ocupação principal, atividade que exercia no momento da infecção) limitaram uma análise mais precisa destes fatores epidemiológicos.

\section{Resultados}

Em todos os anos do período de 1987 a 2004 foram diagnosticados casos de leishmaniose tegumentar americana das mesorregiões em pauta, no LEPAC/UEM, somando um total de 1.938 casos, com uma média de 107,7 casos por ano. Notou-se que o número de casos aumentou após 1993, atingindo um pico em 1994 (175 casos), diminuindo após 1996. Em 2002, novamente os casos aumentaram, chegando a 180 em 2004 (Figura 1).

Na Tabela 1, observa-se que os 1.938 casos de leishmaniose tegumentar americana se distribuíram em 79 dos 162 municípios das mesorregiões deste estudo. Os municípios com maior número de casos registrados foram Maringá (458), Doutor Camargo (126), São Jorge do Ivaí (121), Terra Boa (114), Cianorte (98), Colorado (95), Sarandi (88), Paiçandu (74), Nova Esperança (71), Mandaguaçu (71) e Lobato (70), somando 1.386 casos $(71,5 \%)$. Do total de casos, $1.297(66,9 \%)$ eram do sexo masculino (Tabela 1). Dos 1.789 (92,3\%) casos da doença com informação sobre o local de residência, 688 (38,5\%) habitavam na zona rural e $1.101(61,5 \%)$ na urbana.

Dos 1.938 casos de leishmaniose tegumentar americana, 1.759 (90,7\%) informaram o município onde provavelmente ocorreu a infecção. Destes, 1.609 (91,5\%) indivíduos se infectaram nas mesorregiões norte central, centro ocidental e noroeste (Tabela 2) e 150 (8,5\%) em outros estados ou no Paraguai. Entre os municípios paranaenses destacaram-se São Jorge do Ivaí (181 casos; 11,2\%), Doutor Camargo (153 casos; 9,5\%), Maringá (143 casos; 8,9\%), Terra Boa (127 casos; $7,9 \%$ ), Jussara (101 casos; $6,3 \%$ ), Cianorte (91 casos; $5,6 \%$ ), Colorado ( 87 casos; $5,4 \%$ ) e Lobato (82 casos; $5,1 \%$ ), que juntos perfizeram $59,9 \%$ dos ca- 
Distribuição anual dos casos de leishmaniose tegumentar americana diagnosticados no Laboratório de Ensino e Pesquisa da Universidade Estadual de Maringá, no Estado do Paraná, Brasil, de 1987 a 2004.

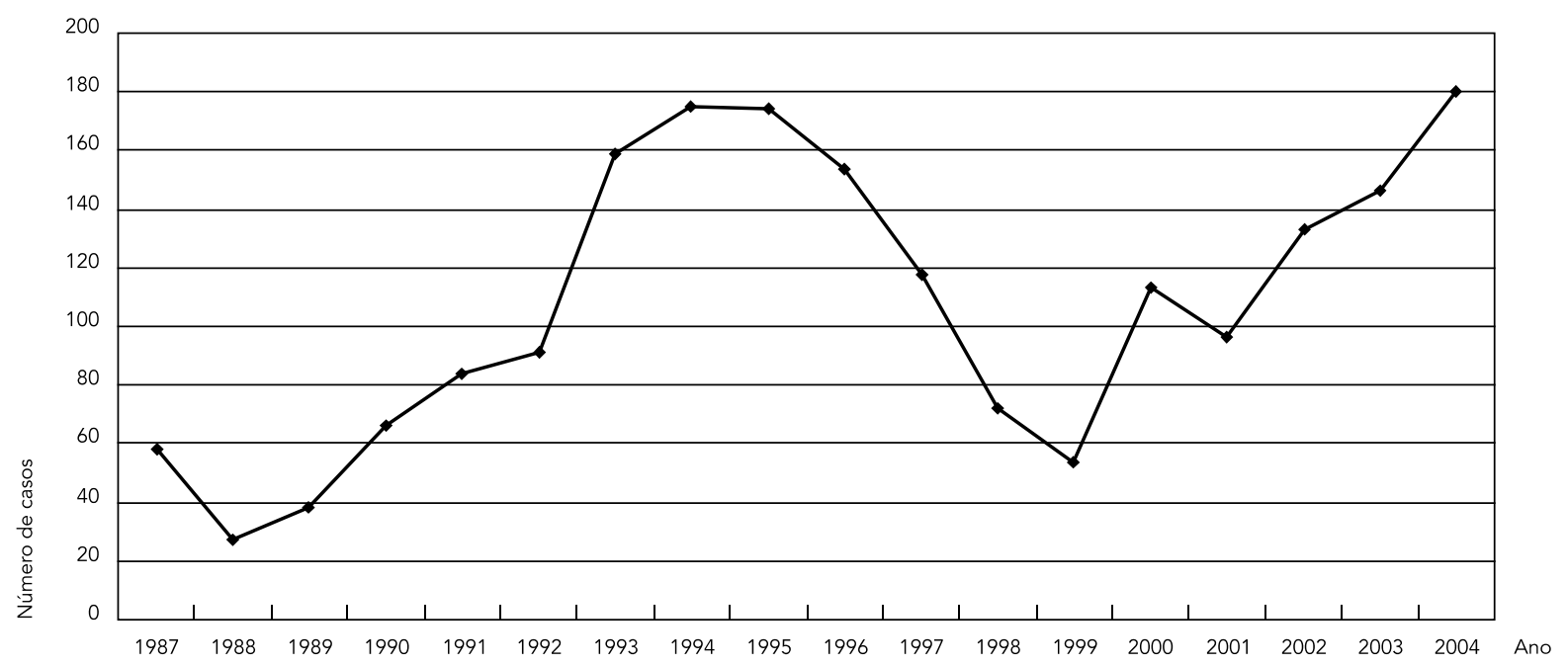

sos que adquiriram a infecção nas mesorregiões do estudo (Tabela 2).

A distribuição geográfica dos casos de leishmaniose tegumentar americana no LEPAC/UEM (Figura 2), segundo o município mais provável de infecção, demonstrou que estes se concentraram em duas grandes áreas: a primeira, mais ao norte, abrange os municípios de Colorado e Lobato, e a segunda, ao sul, os municípios de Doutor Camargo, São Jorge do Ivaí, Jussara, Ivatuba, Terra Boa, Ourizona e Cianorte.

De 1.461 (75,4\% do total) casos, havia informação sobre a idade e também sobre o local mais provável de infecção e, destes, 794 (54,3\%) foram classificados como alóctones e 667 (45,7\%) como autóctones.

Dos 667 casos autóctones (Figura 3a), as faixas etárias mais acometidas foram aquelas entre 2024 anos (67), 30-34 (66), 15-19 (61) e 35-39 anos (55). Os casos entre os indivíduos jovens (0-19 anos), somaram 149 (22,3\%), sendo 61 entre 1519 anos, 43 entre 10-14, 27 entre 5-9 e 18 entre 0-4 anos. Os indivíduos acima de 60 anos somaram 98 casos $(14,7 \%)$. O caso autóctone mais jovem tinha três meses e o mais velho 91 anos. A média etária dos casos autóctones foi de 38,8 anos.

$\mathrm{Na}$ Figura 3b, verifica-se que houve uma concentração dos 794 casos alóctones nas faixas etárias entre 25-49 anos (493 casos; 62,1\%). Nessa categoria, as faixas etárias mais acometidas fo- ram aquelas entre 40-44 anos (119 casos), 35-39 (99), 30-34 (97) e 45-49 anos (94). Os casos entre os indivíduos jovens (0-19 anos) somaram 53 $(6,7 \%)$, sendo 40 entre 15-19 anos, 10 entre 10-14 e 3 entre 5-9 anos. Entre os idosos, somaram-se $102(12,8 \%)$ casos. O caso alóctone mais jovem tinha cinco anos e o mais velho 83. A média etária dos casos alóctones foi de 40,9 anos. Dos casos alóctones, 363 (45,7\%) infectaram-se num dos municípios das mesorregiões do estudo, que não o de residência, 281 (35,4\%) no mesmo município de residência, porém fora do domínio domiciliar e $150(18,9 \%)$ em outros estados ou no Paraguai.

Todos os 150 casos alóctones que se infectaram em outros estados ou no Paraguai informaram ter moradia permanente no Estado do Paraná, sendo 132 na zona urbana e 18 na rural. Destacaram-se os municípios de Maringá (73 casos), Sarandi (9), Doutor Camargo (8), Paiçandu (8), Colorado (4) e Nova Esperança (4). Os locais de infecção desses casos foram os estados de Mato Grosso (59), São Paulo (23), Rondônia (22), Mato Grosso do Sul (20), Bahia (4), Minas Gerais (4), Pará (2), Roraima (2), Santa Catarina (2), Acre (1), Amazonas (1) e Tocantins (1), bem como o Paraguai (9). Nessa categoria, 132 (88\%) casos são do sexo masculino, com idades entre 18 e 81 anos (média: 42,8 anos) e 18 (12\%) do sexo feminino, com idades entre 14 e 76 anos (média: 46,4 anos). 
Casos de leishmaniose tegumentar americana diagnosticados no Laboratório de Ensino e Pesquisa da Universidade Estadual de Maringá, segundo o município de notificação e sexo, no Estado do Paraná, Brasil, de 1987 a 2004.

\begin{tabular}{|c|c|c|c|c|c|c|c|}
\hline Município & $F$ & M & Total & Município & $\mathbf{F}$ & M & Total \\
\hline Alto Paraná & 0 & 3 & 3 & Mandaguari & 12 & 13 & 25 \\
\hline Ângulo & 5 & 3 & 8 & Manoel Ribas & 0 & 1 & 1 \\
\hline Apucarana & 9 & 5 & 14 & Marialva & 19 & 26 & 45 \\
\hline Arapongas & 0 & 7 & 7 & Maringá & 148 & 310 & 458 \\
\hline Astorga & 9 & 7 & 16 & Marumbi & 0 & 1 & 1 \\
\hline Atalaia & 1 & 6 & 7 & Mirador & 1 & 0 & 1 \\
\hline Barbosa Ferraz & 0 & 2 & 2 & Munhoz de Melo & 5 & 5 & 10 \\
\hline Bom Sucesso & 2 & 2 & 4 & Nossa Senhora das Graças & 1 & 5 & 6 \\
\hline Borrazópolis & 1 & 1 & 2 & Nova Cantu & 0 & 1 & 1 \\
\hline Califórnia & 1 & 0 & 1 & Nova Esperança & 26 & 45 & 71 \\
\hline Cambira & 0 & 3 & 3 & Ourizona & 13 & 21 & 34 \\
\hline Campina da Lagoa & 1 & 0 & 1 & Paiçandu & 21 & 53 & 74 \\
\hline Campo Mourão & 0 & 3 & 3 & Paraíso do Norte & 0 & 1 & 1 \\
\hline Cianorte & 28 & 70 & 98 & Paranacity & 4 & 11 & 15 \\
\hline Cidade Gaúcha & 1 & 0 & 1 & Paranapoema & 4 & 1 & 5 \\
\hline Colorado & 27 & 68 & 95 & Paranavaí & 4 & 1 & 5 \\
\hline Corumbataí do Sul & 2 & 0 & 2 & Peabiru & 1 & 1 & 2 \\
\hline Cruzmaltina & 0 & 1 & 1 & Porto Rico & 0 & 1 & 1 \\
\hline Cruzeiro do Sul & 6 & 4 & 10 & Presidente Castelo Branco & 9 & 11 & 20 \\
\hline Doutor Camargo & 43 & 83 & 126 & Quinta do Sol & 0 & 4 & 4 \\
\hline Engenheiro Beltrão & 3 & 7 & 10 & Roncador & 1 & 0 & 1 \\
\hline Fênix & 2 & 6 & 8 & Rondon & 1 & 3 & 4 \\
\hline Floraí & 9 & 15 & 24 & Santa Fé & 7 & 13 & 20 \\
\hline Floresta & 5 & 9 & 14 & Santa Inês & 0 & 1 & 1 \\
\hline Flórida & 2 & 2 & 4 & Santo Antônio do Caiuá & 1 & 1 & 2 \\
\hline Goioerê & 0 & 1 & 1 & Santo Inácio & 0 & 5 & 5 \\
\hline Iguaraçu & 1 & 4 & 5 & São Carlos do Ivaí & 1 & 0 & 1 \\
\hline Inajá & 0 & 4 & 4 & São João do Ivaí & 0 & 1 & 1 \\
\hline Itaguajé & 1 & 2 & 3 & São Jorge do Ivaí & 31 & 90 & 121 \\
\hline Itambé & 7 & 8 & 15 & São José do Ivaí & 1 & 3 & 4 \\
\hline Indianópolis & 1 & 2 & 3 & São Manoel do Paraná & 1 & 5 & 6 \\
\hline Ivailândia & 0 & 1 & 1 & São Pedro do Ivaí & 1 & 0 & 1 \\
\hline Ivatuba & 9 & 24 & 33 & São Tomé & 4 & 11 & 15 \\
\hline Jandaia do Sul & 2 & 4 & 6 & Sarandi & 23 & 65 & 88 \\
\hline Japurá & 7 & 15 & 22 & Tapejara & 1 & 2 & 3 \\
\hline Jussara & 11 & 39 & 50 & Terra Boa & 37 & 77 & 114 \\
\hline Kaloré & 0 & 2 & 2 & Terra Rica & 0 & 1 & 1 \\
\hline Loanda & 0 & 1 & 1 & Tuneiras do Oeste & 0 & 1 & 1 \\
\hline Lobato & 30 & 40 & 70 & Uniflor & 7 & 10 & 17 \\
\hline Mandaguaçu & 29 & 42 & 71 & Total & 641 & 1.297 & 1.938 \\
\hline
\end{tabular}

F: Feminino; M: Masculino.

Dos 363 casos que provavelmente se infectaram num município do Paraná que não o de residência, $5(1,4 \%)$ moravam na zona rural e 358 $(98,6 \%)$ na zona urbana do município de residência. Destacaram-se pela evasão os municípios de Jussara (42 casos), Terra Boa (20), São Jorge do
Ivaí (14), Colorado (12), Maringá (11) e Doutor Camargo (10). Porém, os municípios de Maringá (211 casos), Sarandi (58), Paiçandu (42), Mandaguaçu (19), Nova Esperança (18) e Marialva (13) destacaram-se principalmente como centros de recepção. Nessa situação, $332(91,5 \%)$ casos são 
Casos de leishmaniose tegumentar americana diagnosticados no Laboratório de Ensino e Pesquisa da Universidade Estadual de Maringá, conforme os municípios onde provavelmente ocorreram as infecções, no Estado do Paraná, Brasil, de 1987 a 2004.

\begin{tabular}{|c|c|c|c|}
\hline Município & Número de casos & Município & Número de casos \\
\hline Alto Paraná & 3 & Mandaguari & 23 \\
\hline Ângulo & 7 & Marialva & 32 \\
\hline Apucarana & 12 & Marilena & 1 \\
\hline Arapongas & 6 & Mariluz & 1 \\
\hline Assaí & 2 & Maringá & 143 \\
\hline Astorga & 16 & Marumbi & 1 \\
\hline Atalaia & 6 & Munhoz de Melo & 9 \\
\hline Bandeirantes & 1 & Nossa Senhora das Graças & 5 \\
\hline Barbosa Ferraz & 1 & Nova Cantu & 1 \\
\hline Bom Sucesso & 2 & Nova Esperança & 53 \\
\hline Borrazópolis & 2 & Ourizona & 27 \\
\hline Califórnia & 1 & Paiçandu & 22 \\
\hline Cambira & 4 & Paraíso do Norte & 1 \\
\hline Campina da Lagoa & 1 & Paranacity & 13 \\
\hline Campo Mourão & 2 & Paranapoema & 11 \\
\hline Cianorte & 91 & Paranavaí & 6 \\
\hline Cidade Gaúcha & 2 & Peabiru & 4 \\
\hline Colorado & 87 & Pérola & 1 \\
\hline Corumbataí do Sul & 2 & Porto Rico & 7 \\
\hline Cruzeiro do Sul & 10 & Presidente Castelo Branco & 15 \\
\hline Cruzmaltina & 1 & Querência do Norte & 7 \\
\hline Diamante do Norte & 1 & Quinta do Sol & 4 \\
\hline Doutor Camargo & 153 & Roncador & 1 \\
\hline Engenheiro Beltrão & 18 & Rondon & 3 \\
\hline Fênix & 9 & Santa Fé & 17 \\
\hline Floraí & 20 & Santa Inês & 2 \\
\hline Floresta & 18 & Santo Antônio do Caiuá & 2 \\
\hline Flórida & 4 & Santo Inácio & 5 \\
\hline Formosa do Oeste & 2 & São Carlos do Ivaí & 4 \\
\hline Goioerê & 1 & São João do Caiuá & 1 \\
\hline Icaraíma & 1 & São João do Ivaí & 1 \\
\hline Iguaraçu & 5 & São Jerônimo da Serra & 1 \\
\hline Inajá & 8 & São Jorge do Ivaí & 181 \\
\hline Indianópolis & 3 & São Jorge do Patrocínio & 1 \\
\hline Itaguajé & 4 & São Manoel do Paraná & 6 \\
\hline Itambé & 15 & São Pedro do Ivaí & 1 \\
\hline Ivaté & 1 & São Pedro do Paraná & 1 \\
\hline Ivatuba & 38 & São Tomé & 17 \\
\hline Jandaia do Sul & 3 & Sarandi & 15 \\
\hline Japurá & 16 & Tapejara & 1 \\
\hline Jardim Olinda & 2 & Terra Boa & 127 \\
\hline Jesuítas & 1 & Terra Rica & 1 \\
\hline Jussara & 101 & Tuneiras do Oeste & 1 \\
\hline Loanda & 1 & Umuarama & 2 \\
\hline Lobato & 82 & Uniflor & 14 \\
\hline Londrina & 2 & Vila Alta & 4 \\
\hline Mandaguaçu & 45 & Total & 1.609 \\
\hline
\end{tabular}


Distribuição geográfica dos casos de leishmaniose tegumentar americana nas mesorregiões norte central, centro ocidental e noroeste do Estado do Paraná, Brasil, conforme prováveis locais de infecção, de 1987 a 2004.


1 porto - 1 caso

do sexo masculino, com idades entre cinco e 83 anos (média: 40,8 anos) e 31 (8,5\%) do sexo feminino, com idades entre seis e 78 anos (média: 36,5 anos), sugerindo maior mobilidade do sexo masculino no âmbito intra-regional.

Entre os 281 casos que provavelmente adquiriram a infecção no município de residência, porém fora do domínio domiciliar, 38 (13,5\%) residiam na zona urbana e $243(86,5 \%)$ na rural. Destacaram-se os municípios de São Jorge do Ivaí (35 casos), Doutor Camargo (34), Colorado (30), Lobato (19), Terra Boa (17), Ivatuba (14) e
Maringá (14). Nessa categoria, 233 (82,9\%) casos são do sexo masculino, com idades entre oito e 70 anos (média: 36,9 anos) e $48(17,1 \%)$ do sexo feminino, com idades entre cinco e 74 anos (média: 32,5 anos)

Verificou-se que dos indivíduos com idade maior ou igual a 10 anos, houve informação sobre a ocupação principal para 1.624 casos (84\%). Destes, 571 (35,2\%) exerciam ocupações do setor primário, 259 (15,9\%) eram donas-de-casa, $181(11,1 \%)$ empregados do setor terciário, 176 (10,8\%) autônomos do setor terciário, 139 (8,6\%) 


\section{Figura 3}

Faixas etárias dos casos autóctones e alóctones de leishmaniose tegumentar americana diagnosticados no Laboratório de Ensino e Pesquisa da Universidade Estadual de Maringá, no Estado do Paraná, Brasil, de 1987 a 2004.

3a) Autóctones

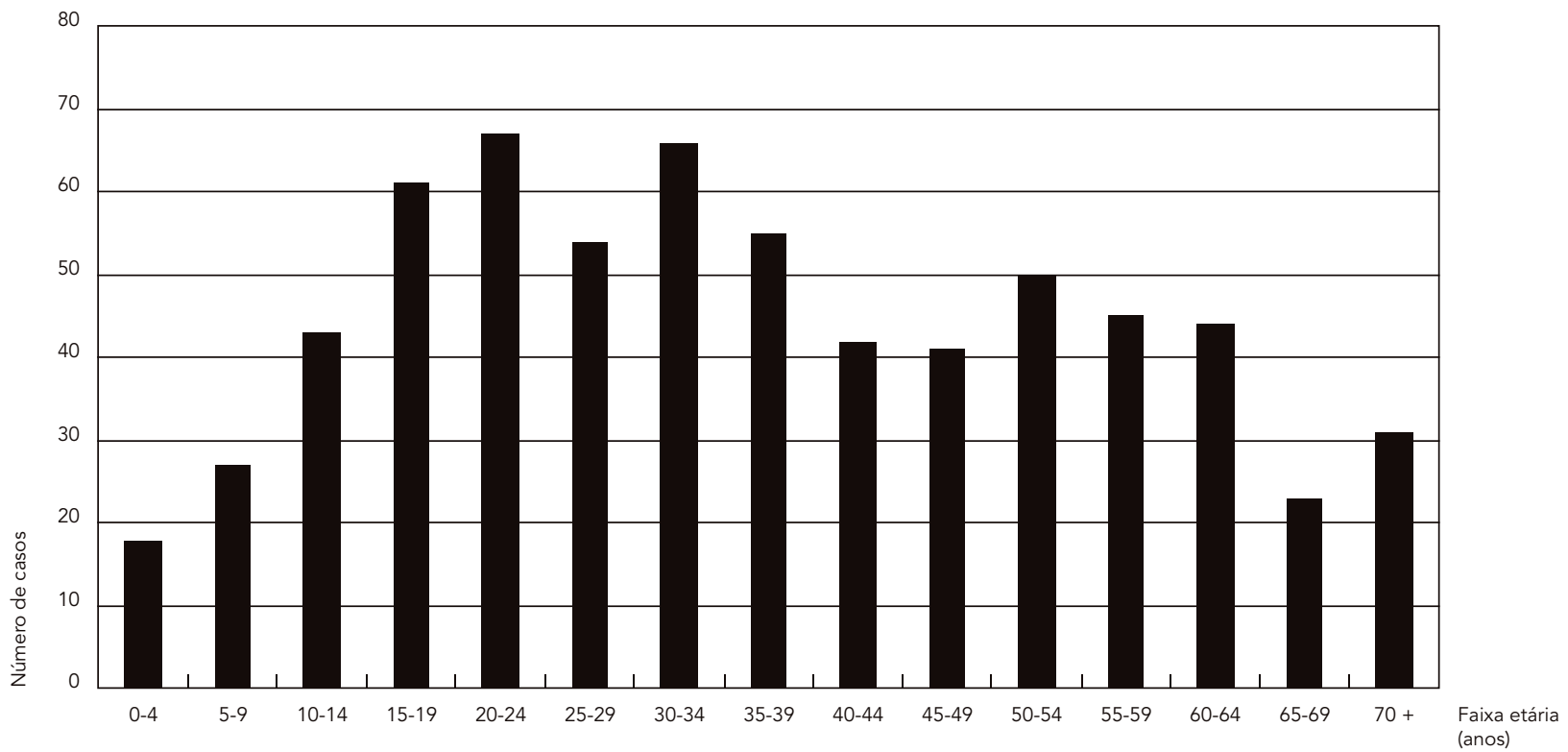

3b) Alóctones

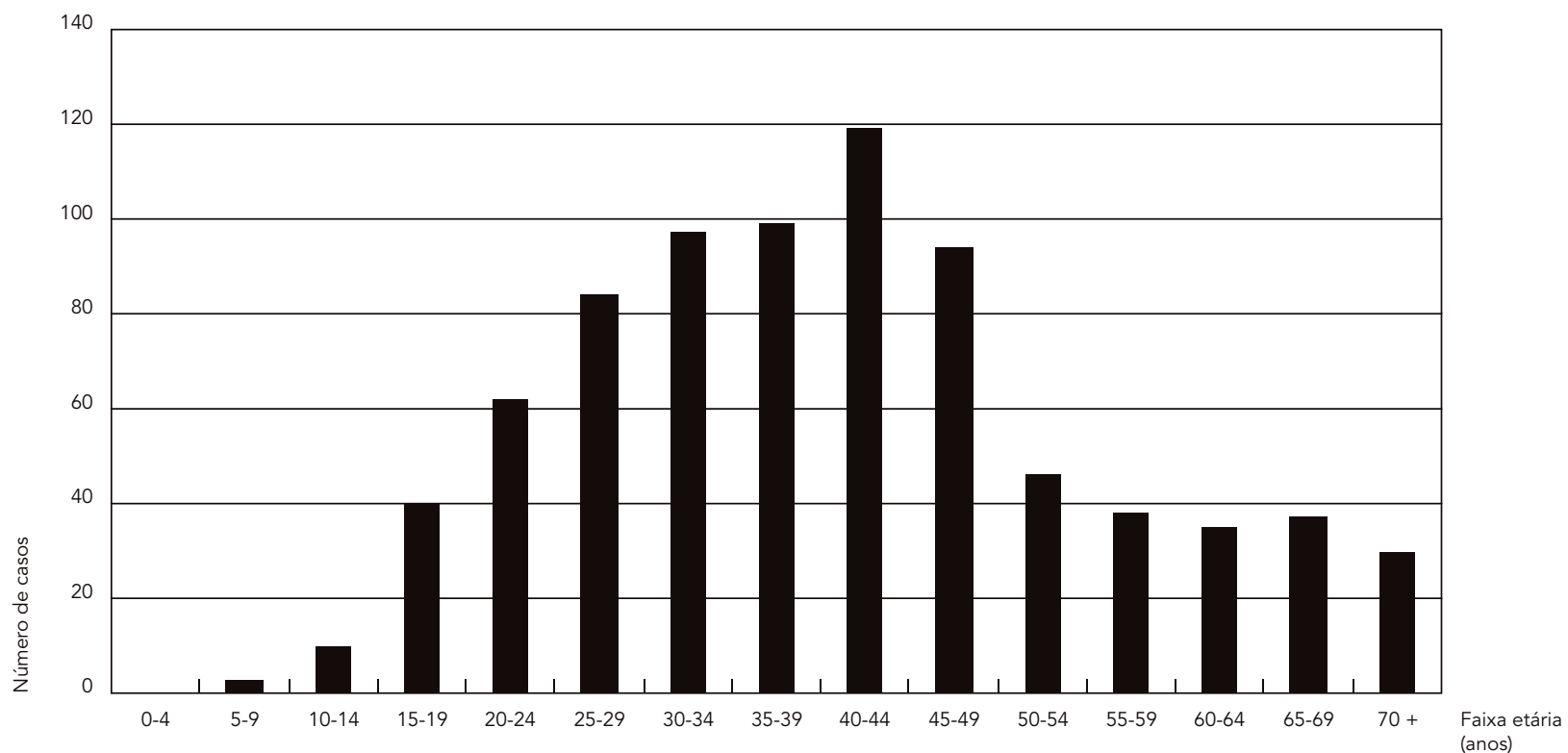


aposentados, $121(7,4 \%)$ estudantes, 84 (5,2\%) operários do setor secundário, 63 (3,9\%) motoristas, $21(1,3 \%)$ desempregados e $9(0,6 \%)$ exerciam outras ocupações.

Observou-se que de 971 casos com tipo de moradia informado, 481 (49,5\%) eram de madeira sem forro, $198(20,4 \%)$ de madeira com forro, $122(12,6 \%)$ de alvenaria sem forro, $160(16,5 \%)$ de alvenaria com forro e 10 (1\%) de moradias precárias.

\section{Discussão}

Os trabalhos sobre a leishmaniose tegumentar americana no Paraná vêm confirmando a natureza endêmica da doença neste estado 3,4,5. Observou-se que em todos os anos do período de 1987 a 2003 houve atendimento de casos de leishmaniose tegumentar americana no LEPAC/UEM, provenientes das mesorregiões norte central, centro ocidental e noroeste, mostrando que estas mesorregiões são endêmicas 4,5 e inserem-se no circuito de produção de leishmaniose tegumentar americana do Paranapanema 22. O recrudescimento da doença no triênio 19931995 e mais recentemente, de 2002-2004, mostra que a mesma assumiu dimensões epidêmicas nestes períodos, coincidindo com o aumento do número de casos no Estado do Paraná 3,4.

A proporção de casos autóctones com idade entre 1-20 anos (22,3\%) é maior do que a que foi registrada para os casos alóctones $(6,7 \%)$. A ocorrência de leishmaniose tegumentar americana em menores de cinco anos de idade (incluindo um bebê de três meses e dois de seis meses) foi verificada apenas entre os casos autóctones. Além disso, entre os casos autóctones, o número de mulheres afetadas pela doença foi semelhante ao de homens, o que também não coincidiu com o que aconteceu entre os casos alóctones. A grande proporção de casos envolvendo jovens de ambos os sexos, especialmente na faixa etária até 14 anos, e de mulheres, que provavelmente adquiriram a infecção no peridomicílio e domicílio, sugere a existência de um ciclo de transmissão domiciliar e peridomiciliar nessas mesorregiões do Estado do Paraná. Apesar desses casos apresentarem, na grande maioria, moradia permanente na zona rural, o risco não parece estar ligado ao trabalho agrícola, já que a proporção de pessoas ocupadas com atividades domésticas foi semelhante àquela das pessoas envolvidas com o trabalho rural; o grande contingente de donasde-casa, estudantes, crianças e aposentados, no presente estudo, corrobora esta afirmação.

Os estudos realizados até o momento no Paraná 3,4,5,6,7,8,9,10,11 fazem menções, geralmente discretas, sobre a organização do espaço rural, influenciando na epidemiologia da leishmaniose tegumentar americana no estado, incluindo a transmissão domiciliar e peridomiciliar nas áreas agrícolas de colonização antiga. A construção de galinheiros, chiqueiros de porcos, estábulos e anexos para a armazenagem das colheitas, sempre muito próximos às residências, cria um ambiente que favorece a circulação de mamíferos silvestres, prováveis reservatórios de Leishmania, uma vez que no peridomicílio há grande disponibilidade de alimentos. Além disso, a presença de animais domésticos no peridomicílio pode ser um fator determinante da quantidade de flebotomíneos no domicílio e está na dependência da distância deste em relação aos abrigos dos animais $6,7,8,9,10,11$. O acúmulo de matéria orgânica (lixo doméstico, fezes de animais domésticos e restos de comida a eles oferecida, folhas e frutos caídos) e a forma inadequada de descarte das águas de uso doméstico que mantêm os solos úmidos, no peridomicílio, são fatores que podem propiciar a formação de criadouros de flebotomíneos 6,7,8,9,10,11. A colonização organizou o espaço rural de tal forma que criou condições ambientais nitidamente favoráveis à transmissão da leishmaniose tegumentar americana.

No processo de colonização, o estado atuou em conjunto com grupos empresariais privados, encarregados de desenhar a nova estrutura fundiária. As empresas colonizadoras atrelaram o processo de venda dos lotes a uma motivação econômica, sempre representada por alternativas de exploração e uso da terra agrícola. No caso das mesorregiões norte central, noroeste e centro ocidental, a principal colonizadora foi a Companhia Melhoramentos do Norte do Paraná, devido, principalmente, às estratégias utilizadas pela loteadora na localização das cidades, no uso da terra, no modelo de estrutura fundiária, na construção de estradas ligando os loteamentos aos centros urbanos próximos e na montagem de sistemas de crédito e de comercialização das safras 23. Essas "obrigações sociais" trouxeram segurança e bem-estar social aos compradores, garantindo o acesso à terra sem problemas com posseiros, grileiros ou indígenas. Publicação divulgada pela empresa 24 (p. 21), a propósito, revela: "As cidades destinadas a se tornarem núcleos econômicos de maior importância seriam demarcadas, a cada 100 quilômetros, uma da outra, aproximadamente. Tanto nas cidades quanto nos patrimônios a área urbana apresentaria uma divisão em datas residenciais e comerciais. Ao redor das áreas urbanas se situariam os cinturões verdes, isto é, uma faixa dividida em chácaras que pudessem servir para a produção de gêneros alimentícios de consumo local, como aves, ovos, fru- 
tas, hortaliças e legumes. A área rural seria cortada por estradas vicinais, abertas de preferência ao longo dos espigões, dividindo a terra em pequenos lotes com a frente voltada para as estradas vicinais e os fundos voltados para o ribeirão. Na parte mais alta dos lotes, apropriada para o plantio de café, o proprietário da gleba desenvolveria sua atividade agrícola básica. Na parte mais baixa, construiria sua casa, cultivaria a horta e o pomar e criaria seus animais para consumo próprio. A água seria obtida no ribeirão ou de poços. As casas de vários lotes contíguos, alinhadas nas margens dos cursos d'água, formariam comunidades que evitassem o isolamento das famílias e favorecessem o trabalho em mutirão, principalmente nas colheitas de café".

A estrutura fundiária rural originada por esse modelo de ocupação permanece até hoje e, talvez por isto, a grande maioria dos casos de leishmaniose tegumentar americana investigados remete à presença do indivíduo, temporária ou permanente, ao vale onde se situa sua residência, onde ainda existe uma mata rala ou capoeira densa que acompanha os cursos d'água. As propriedades agrícolas pertencentes à Companhia Melhoramentos do Norte do Paraná, que mantém o modelo antigo de organização, continuam focos ativos de produção da leishmaniose tegumentar americana, em Jussara e Terra Boa 3. Da mesma forma que os casos rurais autóctones, os urbanos estão intimamente relacionados com o modelo de urbanização empregado na região, já que grande parte das infecções ocorre nos cinturões verdes das cidades, onde existem fragmentos de matas nativas modificadas próximo dos domicílios, como observado nos municípios de Cianorte 5 e Maringá. A freqüência e a densidade de flebotomíneos no domicílio e peridomicílio depende da presença de mata residual e da distância desta em relação às casas 6,7,8,9,10,11, fato que parece constituir a base da persistência da leishmaniose tegumentar americana na sua forma zoonótica, no Paraná.

As áreas que se destacaram por sua densidade intensa de casos localizam-se precisamente nas bacias dos rios Ivaí (municípios de Doutor Camargo, São Jorge do Ivaí, Jussara, Ivatuba, Terra Boa e Ourizona) e Pirapó (municípios de Colorado e Lobato), onde foram preservadas grandes manchas da floresta original, pouco alterada. Possivelmente, os encraves de vegetação nativa ou pouco modificada, circundados pelo ambiente degradado pelo processo agropecuário, funcionem como refúgios ecológicos para vetores e reservatórios de Leishmania. Pela proximidade dos domicílios com os encraves de mata, na maioria das propriedades rurais, o risco de infecção dos habitantes se torna elevado, já que flebo- tomíneos infectados provenientes dos refúgios alcançam facilmente os domicílios e o peridomicílio. Além disso, os reservatórios podem circular no peridomicílio, onde vetores provenientes dos criadouros peridomiciliares podem se infectar. A necessidade dos encraves de vegetação e a localização dos focos de maior produção nas localidades com as maiores áreas de mata preservada, apesar da existência de todas as condições para o estabelecimento de um ciclo peridomiciliar, sugerem que este é dependente do ciclo silvestre nas mesorregiões em estudo.

Além dos fatores acima citados, o tipo de moradia reforça a ocorrência da transmissão domiciliar na área. Verificou-se que as pessoas atingidas pela doença freqüentemente habitavam casas rústicas de madeira ou de alvenaria sem forro. Esse fato pode ser considerado um fator de risco para a transmissão domiciliar de leishmaniose tegumentar americana, pois nesses tipos de moradia é difícil evitar o acesso e a permanência dos flebotomíneos, seja pela ineficácia da aplicação de inseticidas por borrifação ou pela presença de pontos permanentemente abertos que favorecem a inclusão destes insetos nos domicílios, a despeito da tendência endofílica de $N$. whitmani 25 e $N$. neivai 6,26 , espécies dominantes nessa região 6,7,8,9.

A crise que se instalou sobre a cafeicultura, em especial a paranaense, sobretudo durante a década de 1970, conjugada com fatores de ordens conjuntural (contração do mercado, superprodução e dependência econômica externa), estrutural (política oficial de modernização agrícola) e local (ocorrência de geadas quase que anuais e contaminação dos cafeeiros pela "ferrugem"), articulados com o processo de modernização agrícola, culminaram por reduzir violentamente a área ocupada pela cafeicultura no Estado do Paraná 27. Além disso, a promulgação de uma legislação social moderna para o setor agrícola e sua fiscalização ocasionaram a rescisão de vários contratos de trabalho rural fixo e um aproveitamento da mão-de-obra no sistema volante ou diarista 27,28 .

Como o pólo da cafeicultura estadual situava-se ao norte do estado, é evidente que as mudanças decorrentes da transformação da agricultura, sobretudo na estrutura fundiária e na distribuição espacial da população, fossem expressivas 27 . Assim, durante a década de 1970, verificou-se uma redução maciça do número de estabelecimentos rurais no norte do estado. Da mesma forma, no aspecto demográfico, nesse mesmo período, o decréscimo populacional do Paraná atingiu 1.168.000 pessoas, sendo que na zona rural o saldo negativo foi de 2.647 .000 e na urbana ocorreu um saldo positivo de 1.355.000, 
indicando um intenso processo migratório rural-urbano ${ }^{29}$. A desestabilização rural se torna visível pelo número reduzido de trabalhadores rurais com contratos permanentes, pela segregação forçada e economicamente desfavorável do local de residência e de trabalho, e pelo emprego predominante de trabalhadores volantes 28 .

A concentração dos casos alóctones na faixa etária de 25-49 anos, a baixa incidência na população infantil, a inexistência de casos em menores de cinco anos e o predomínio do sexo masculino na faixa etária mencionada evidencia o perfil ocupacional dos casos de leishmaniose tegumentar americana. Como a maioria dos indivíduos reside na zona urbana, mas adquiriu a infecção na zona rural, é muito provável que o trabalho agrícola volante desenvolvido pelos moradores das cidades tenha contribuído para o grande número de casos de leishmaniose tegumentar americana em moradores da zona urbana. Esses são, geralmente, antigos ocupantes da zona rural que migraram para a sede dos municípios mais dinâmicos da própria região, porém continuam a desenvolver atividades agrícolas, pois a baixa qualificação profissional dificulta a absorção dos mesmos pelo restrito mercado de trabalho urbano. A migração devida à rotatividade e à informalidade do trabalho rural parece constituir importante fator de risco para leishmaniose tegumentar americana nas mesorregiões norte central, centro ocidental e noroeste do Estado do Paraná.

O número expressivo de casos com provável local de infecção em outros estados, especialmente da Amazônia Legal, permite inferir que muitos habitantes do Estado do Paraná vêm buscando oportunidades de trabalho nesta região. Esse fato fica claro quando se nota que a grande maioria dos indivíduos nessa situação é do sexo masculino em idade produtiva, com residência permanente na zona urbana dos municípios paranaenses. A migração para a Região Amazônica nas últimas décadas, apoiada direta ou indiretamente pelo governo federal por meio de projetos desorganizados de colonização e construção de estradas, é um fator interveniente importante na ocorrência da leishmaniose tegumentar americana ${ }^{30}$. Em muitos casos os migrantes não se adaptam bem, devido ao novo sistema agrícola vigente e pela perda dos laços familiares e comunitários, retornando à sua origem. Ressalta-se que a atividade de garimpagem, que se tornou atraente para uma parcela dessa população, é desenvolvida em muitos casos em garimpos sem condições mínimas de saneamento, higiene e segurança do trabalho.

No transcurso dessa realidade, fica patente o processo de concentração da posse da terra.
À medida que essa se acentuou, milhares de pessoas viram-se expulsas do campo, tornando maior o fluxo do êxodo rural, constituindo, na sua maioria, os subempregados, trabalhadores volantes, sem-terra, sem-teto e desempregados. Face à velocidade do fenômeno, as cidades não tiveram recursos para se equiparem para atender os retirantes do campo 29 a exemplo das principais cidades do Estado do Paraná 27. É considerável, hoje, o número de habitantes das cidades tidos como urbanos, mas que constituem mão-de-obra para as atividades temporárias do campo 31 .

Além do desemprego nas cidades, as características da agricultura atual impulsionaram a rotatividade do trabalho rural. As culturas de cana-de-açúcar, mandioca, soja, trigo e milho, por serem temporárias, necessitam de mão-de-obra no plantio e colheita, requerendo trabalhadores apenas nestas etapas. As culturas mecanizadas, por sua vez, exigem não trabalhadores propriamente agrícolas, mas sim profissionais autônomos como motoristas e operadores de máquinas, na colheita e transporte das safras. Os subsídios para o cultivo da soja e da cana-de-açúcar, em especial, concorreram para o avanço destas culturas sobres as antigas áreas cafeeiras, resultando num processo de concentração fundiária e numa significativa melhoria na infra-estrutura viária e de armazenamento de produtos agrícolas em geral ${ }^{32}$. Mas resultou, também, na redução das áreas florestais, tanto as de topo como as matas dos vales fluviais, uma vez que os cultivos mecanizados passaram a ocupar, em muitos casos, a quase totalidade da propriedade rural. As localidades Distrito de Alto Alegre (Município de Colorado), Iguatemi (Município de Maringá) e Fazenda Jussara (Município de Jussara), constituem focos de produção de leishmaniose tegumentar americana, possivelmente relacionados com o trabalho rotativo em áreas de influência das destilarias de álcool existentes nestas localidades.

\section{Conclusões}

Verificou-se que a leishmaniose tegumentar americana tem plena distribuição nas mesorregiões em apreço e que as condições necessárias à produção da leishmaniose tegumentar americana possivelmente foram criadas no processo de organização do espaço rural das mesorregiões do estudo, particularmente na colonização e, posteriormente, com a crise da monocultura cafeeira.

Como um grande contingente de indivíduos residentes na zona urbana adquiriu a infecção na zona rural, sugere-se que a migração pendular constitui importante fator de risco para leishma- 
niose tegumentar americana nas mesorregiões norte central, centro ocidental e noroeste do Estado do Paraná. Deve-se salientar a importância

\section{Resumo}

Analisa-se a epidemiologia da leishmaniose tegumentar americana em municípios das mesorregiões norte central, centro ocidental e noroeste do Estado do Paraná, Brasil. O diagnóstico dos casos de leishmaniose tegumentar americana foi realizado na Universidade Estadual de Maringá, de 1987 a 2004. Conforme o provável local de infecção, os casos foram divididos em autóctones (infectaram-se no domínio doméstico) ou alóctones (infectaram-se fora do domínio doméstico). Observou-se que em todos os anos do período houve atendimento de casos provenientes das mesorregiões supracitadas. Os municípios com maior número de casos notificados foram Maringá (458), Doutor Camargo (126), São Jorge do Ivaí (121), Terra Boa (114), Cianorte (98) e Colorado (95). De 1.938 casos, 66,9\% eram do sexo masculino. Entre 667 casos autóctones, o número de mulheres afetadas pela doença foi semelhante ao de homens, com casos em menores de cinco anos de idade, fatos que não ocorreram entre os 794 casos alóctones. As condições necessárias à produção da leishmaniose tegumentar americana foram criadas no processo de construção do espaço rural das mesorregiões em pauta, particularmente no modelo de colonização e na crise da monocultura cafeeira.

Leishmaniose; Vigilância Epidemiológica; Conglomerados Espaço-Temporais

\section{Colaboradores}

U. Teodoro e M. E. M. C. Ferreira orientaram a realização do trabalho e participaram na elaboração do manuscrito. M. V. C. Lonardoni e T. G. V. Silveira contribuíram na elaboração do manuscrito. W. M. Monteiro e H. C. Neitzke contribuíram com a coleta dos dados e na elaboração do manuscrito. dos estudos de espacialização dessa endemia para precisar as ações de políticas públicas voltadas ao controle da mesma.

\section{Referências}

1. Ministério da Saúde. Leishmaniose tegumentar americana - distribuição de casos confirmados de LTA de 1980 a 2005. http://dtr2001.saude.gov. $\mathrm{br} / \mathrm{svs} /$ epi/situacao_doencas/planilhas_doencas. htm (acessado em 12/Dez/2006).

2. Luz E, Membrive N, Castro EA, Dereure J, Pratlong F, Dedet JA, et al. Lutzomyia whitmani (Diptera: Psychodidae) as vector of Leishmania (V.) braziliensis in Paraná state, southern Brazil. Ann Trop Med Parasitol 2000; 94:623-31.

3. Silveira TG, Teodoro U, Lonardoni MVC, Guilherme AL, Toledo MJO, Ramos M, et al. Aspectos epidemiológicos da leishmaniose tegumentar em área endêmica do Estado do Paraná, Brasil. Cad Saúde Pública 1996; 12:141-7.

4. Silveira TGV, Arraes SMAA, Bertolini DA, Teodoro U, Lonardoni MVC, Roberto ACBS, et al. Observações sobre o diagnóstico laboratorial e a epidemiologia da leishmaniose tegumentar no Estado do Paraná, sul do Brasil. Rev Soc Bras Med Trop 1999; 32:413-23.

5. Lima AP, Minelli L, Comunello E, Teodoro U. Distribuição da leishmaniose tegumentar por imagens de sensoreamento remoto orbital, no Estado do Paraná, Sul do Brasil. An Bras Dermatol 2002; 77:681-92.

6. Teodoro U, Silveira TGV, Santos AR, Santos DR, Santos ES, Oliveira O, et al. Freqüência da fauna de flebotomíneos no domicílio e em abrigos de animais domésticos no peridomicílio, nos municípios de Cianorte e Doutor Camargo, Estado do Paraná, Brasil. Rev Patol Trop 2001; 30:209-24.

7. Membrive NA, Rodrigues G, Membrive U, Monteiro WM, Neitzke HC, Lonardoni MVC, et al. Flebotomíneos de municípios do norte do Estado do Paraná, sul do Brasil. Entomol Vectores 2004; 11:673-80.

8. Teodoro U, Santos DR, Santos AR, Oliveira O, Santos ES, Neitzke HC, et al. Avaliação de medidas de controle de flebotomíneos no Município de Lobato, Estado do Paraná, Sul do Brasil. Cad Saúde Pública 2006; 22:415-55. 
9. Teodoro U, Santos DR, Santos AR, Oliveira O, Poiani LP, Silva AM, et al. Informações preliminares sobre flebotomíneos do norte do Paraná. Rev Saúde Pública 2006; 40:327-30.

10. Teodoro U, Balduíno J, Thomaz-Soccol V, Barbosa OC, Ferreira MEMC, Lozovei AL, et al. Environmental sanitation and peridomiciliar organisation as auxiliary practices for the control of phlebotomines in Paraná State, Southern Brazil. Braz Arch Biol Technol 1999; 42:307-14.

11. Teodoro U, Silveira TGV, Santos DR, Santos ES, Santos AR, Oliveira O, et al. Influência da reorganização, da limpeza e da desinsetização de edificações na densidade populacional de flebotomíneos, no Município de Doutor Camargo, Estado do Paraná, Brasil. Cad Saúde Pública 2003; 19:1801-13.

12. Velásquez LG, Membrive NA, Membrive U, Rodrigues G, Reis N, Lonardoni MVC, et al. PCR in the investigation of canine American tegumentary leishmaniasis in northwestern Paraná State, Brazil. Cad Saúde Pública 2006; 22:571-8.

13. Zanzarini PD, Santos DR, Santos AR, Oliveira O, Poiani LP, Lonardoni MVC, et al. Leishmaniose tegumentar americana canina em municípios do norte do Estado do Paraná, Brasil. Cad Saúde Pública 2005; 21:1957-61.

14. King RJ, Campbell-Lendrum DH, Davies CR. Predicting geographic variation in cutaneous leishmaniasis, Colombia. Emerg Infect Dis 2004; 10: 598-607.

15. Machado LO. A fronteira agrícola no Brasil. In: Becker B, Christofoletti A, Dadidivich FR, Geiger PP, organizadores. Geografia e meio ambiente no Brasil. São Paulo: Editora Hucitec; 1995. p. 35-53.

16. Maack R. Geografia física do Estado do Paraná. 2aa Ed. Rio de Janeiro: Editora José Olímpio; 1981.

17. Instituto Paranaense de Desenvolvimento Econômico e Social. Indicadores e mapas temáticos para o planejamento urbano e regional. Curitiba: Instituto Paranaense de Desenvolvimento Econômico e Social; 2003.

18. Santos M. A natureza do espaço - técnica e tempo, razão e emoção. São Paulo: Editora Hucitec; 1996.

19. Santos M. O espaço em questão. São Paulo: Marco Zero/AGB; 1988.

20. Menezes MA. Questionamentos às categorias "migrante de retorno" e "migrante". In: Anais da I Conferência sobre "A Questão Regional e os Movimentos Sociais no Terceiro Mundo". Rio Claro: Associação de Geografia Teorética; 1992. p. 44.
21. Rosaldo MZ, Lamphere L. Woman, culture and society. Stanford: Stanford University Press; 1974. p. 189-206.

22. Fundação Nacional de Saúde. Vigilância e monitoramento da leishmaniose tegumentar americana em unidades territoriais-Brasil, 1994-2001. http:// www.funasa.gov.br (acessado em 05/Fev/2005).

23. Serra E. Reflexos sobre a origem da crise agrária no Norte do Paraná. Boletim de Geografia 2001; 19:45-58.

24. Companhia Melhoramentos do Norte do Paraná. Colonização e desenvolvimento do Norte do Paraná. São Paulo: Companhia Melhoramentos do Norte do Paraná; 1975.

25. Vexenat JA, Barretto AC, Cuba-Cuba C, Marsden PD. Características epidemiológicas da leishmaniose tegumentar americana em uma região endêmica do Estado da Bahia. III. Fauna flebotomínica. Mem Inst Oswaldo Cruz 1986; 81:293-301.

26. Casanova C, Costa AIP, Natal D. Dispersal pattern of the sand fly Lutzomyia neivai (Diptera: Psychodidae) in a cutaneous leishmaniasis endemic rural area in Southeastern Brazil. Mem Inst Oswaldo Cruz 2005; 100:719-24.

27. Moro DA. Desenvolvimento econômico e dinâmica espacial da população no Paraná contemporâneo. Boletim de Geografia 1998; 16:1-55.

28. Kohlhepp G. Mudanças estruturais na agropecuária e mobilidade da população rural no Norte do Paraná (Brasil). Revista Brasileira de Geografia 1991; 53:79-94.

29. Ferreira YN. Industrialização e urbanização do Paraná. Geografia 1985; 3:113-28.

30. Azevedo ACR, Souza NA, Meneses CRV, Costa WA, Costa SM, Lima JB, et al. Ecology of sand flies (Diptera: Psychodidae: Phlebotominae) in the North of the State of Mato Grosso, Brazil. Mem Inst Oswaldo Cruz 2002; 94:459-62.

31. Alegre M, Moro DA. A mobilidade da população nas antigas áreas cafeeiras do norte do Paraná. Boletim de Geografia 1986; 4:28-73.

32. Arbex Jr. J, Olic NB. A hora do Sul. São Paulo: Editora Moderna; 1995.

Recebido em 07/Nov/2006

Versão final reapresentada em 15/Mai/2007

Aprovado em 28/Nov/2007 